\title{
Ferrocene/graphene modified glassy carbon electrode for Chloromycetin detection
}

\author{
Lin Hu, Xiaoqin Zhou*, Jinqing Li, Tongtong Bai, Juan Tang, Tao Zhou, Qujin Cui \\ Institute of Applied Chemistry, East China JiaoTong University, Nanchang, 330013, PR China \\ *E-mail: $1061508795 @$ qq.com
}

doi: 10.20964/2018.01.09

Received: 7 March 2017 / Accepted: 25 September 2017 / Online Published: 1 December 2017

In this study, we used ferrocene/graphene to modify a glassy carbon electrode, which was fixed with an appropriate amount of Nafion solution. The -C-O-C- and - $\mathrm{COOH}$ functional groups were detected in the ferrocene/graphene composite using IR spectroscopy, which indicated that graphene was oxidized to graphene oxide, making it more hydrophilic, dispersible and compatible with polymers, thus increasing the chloromycetin detection rate. A scan rate of $0.05 \mathrm{~V} / \mathrm{s}$ is ideal. The optimal conditions for chloromycetin detection were found using Cyclic voltammetry (CV): a scan rate of 0.05 $\mathrm{V} / \mathrm{s}, \mathrm{pH}$ 6.47, and $0.1 \mathrm{~mol} / \mathrm{L}$ PBS buffer solution. Differential pulse voltammetry(DPV) shows that the concentrations of chloromycetin are $2 \times 10^{-6}-3.2 \times 10^{-5} \mathrm{~mol} / \mathrm{L}$, and there is a good linear relationship between the peak current and the concentration: $I_{p a}(\mu \mathrm{A})=2.44772 \mathrm{c}(\mu \mathrm{mol} / \mathrm{L})-46.14375, \mathrm{r}=0.993$; the detection limit is $4.5 \times 10^{-8} \mathrm{~mol} / \mathrm{L}$. This modified electrode has good stability, repeatability and operability and can be applied to detect actual samples.

Keywords: Ferrocene/graphene-modified electrode; Detection; Chloromycetin; Cyclic voltammetry; Differential pulse voltammetry.

\section{FULL TEXT}

(C) 2018 The Authors. Published by ESG (www.electrochemsci.org). This article is an open access article distributed under the terms and conditions of the Creative Commons Attribution license (http://creativecommons.org/licenses/by/4.0/). 